\title{
Increased micronucleus frequency in peripheral blood lymphocytes predicts the risk of bladder cancer
}

\author{
Barbara Pardini ${ }^{\star, 1,2,8}$, Clara Viberti ${ }^{1,2,8}$, Alessio Naccarati ${ }^{1}$, Alessandra Allione ${ }^{1,2}$, Marco Oderda ${ }^{3}$, \\ Rossana Critelli ${ }^{1}$, Mirko Preto ${ }^{3}$, Andrea Zijno ${ }^{4}$, Giuseppina Cucchiarale ${ }^{5}$, Paolo Gontero ${ }^{3}$, Paolo Vineis ${ }^{1,6}$, \\ Carlotta Sacerdote ${ }^{7}$ and Giuseppe Matullo ${ }^{1,2}$ \\ ${ }^{1}$ Human Genetics Foundation-Torino (HuGeF), via Nizza 52, Turin 10126, Italy; ${ }^{2}$ Department of Medical Sciences, University of Turin, \\ Via Santena 19, Turin 10126, Italy; ${ }^{3}$ Department of Urology, Città della Salute e della Scienza, Corso Bramante 88, Turin 10126, Italy; \\ ${ }^{4}$ Department of Environment and Primary prevention, Istituto Superiore di Sanità, Viale Regina Elena 299, Rome 00161, Italy; \\ ${ }^{5}$ Department of Urology, Clinica Cellini, Via Cellini 5, Turin 10126, Italy; ${ }^{6}$ Department of Epidemiology and Public Health, MRC-HPA \\ Centre for Environment and Health, School of Public Health, Imperial College London, St Mary's Campus, Norfolk Place, London W2 \\ 1PG, UK and 'Unit of Cancer Epidemiology, Center for Cancer Prevention (CPO-Piemonte), Via Santena 7, Turin 10126, Italy
}

Background: Bladder cancer (BC) is among the most common malignancies worldwide. The identification of new biomarkers for early BC detection, recurrence/progression is urgently needed. The cytokinesis-block micronucleus assay (CBMN) evaluates chromosome damage in cultured human lymphocytes and micronuclei (MN) provide a convenient and reliable index of both chromosome breakage and loss.

Methods: Chromosomal damage (expressed as frequencies of MN, nucleoplasmic bridges and nuclear buds (NBUD)) was evaluated by CBMN assay in cryopreserved lymphocytes from 158 age/smoking-matched pairs of cases and controls in relation to $\mathrm{BC}$ risk, recurrence or progression. Moreover, non-muscle invasive BC (NMIBC) patients were characterised for 783 DNA repair gene polymorphisms for their possible association with the investigated cytogenetic end points.

Results: MN and NBUD frequencies were significantly higher in cases than in controls $(P=0.001$ and $P=0.006$, respectively), with the associations being stronger in NMIBC. In a logistic regression model, for each increase of one unit in the MN frequency, a 1.12 increased risk of developing NMIBC was observed. In NMIBC cases, 10 polymorphisms were associated with different MN frequencies after genotype stratification.

Conclusions: A model including traditional BC risk factors, MN frequency and the selected polymorphisms differentially distributed in cases and controls improved BC patient identification. Understanding the meaning of systemic chromosomal damage in BC patients with respect to the general population may help to adopt specific prevention strategies and therapeutic intervention.

Bladder cancer (BC) is the fifth most common malignancy in the general population and its incidence increases with age, which represents the most significant risk factor for it. Men are predominantly affected, with a 3:1 male:female ratio (Ferlay et al, 2015). A wide range of environmental risk factors has been identified among which are tobacco smoking, consumption of arsenic-contaminated water, occupational exposure to aromatic amines and polycyclic hydrocarbons, and chronic infection with

*Correspondence: Dr B Pardini; E-mail: barbara.pardini@hugef.org

${ }^{8}$ These authors contributed equally to this work.

Received 19 July 2016; revised 24 October 2016; accepted 9 November 2016; published online 13 December 2016

(c) 2017 Cancer Research UK. All rights reserved 0007-0920/17 
Schistosoma species (Matullo et al, 2015). Several germline variants have also been recognised as contributors to BC risk (Dudek et al, 2013).

At diagnosis, the majority of $\mathrm{BC}$ are non-muscle invasive (80\%, Stage Ta-T1; NMIBC) and only $20 \%$ of all diagnosed BC cases are muscle-invasive (Stage T2 and above; MIBC). Despite endovesical treatment, NMIBCs frequently recur (50-70\%) and sometimes progress to detrusor muscle invasion (10-15\%; Sylvester et al, 2006). Cystoscopy is the most used way to monitor these patients who frequently undergo multiple endoscopic resections over the years. Risk tables provide a prognostic tool regarding the risk of recurrence and progression of NMIBC, whereas the prognosis of MIBC patients is less favourable due to a high risk of metastatic progression, independently of treatment. Up-to-date, there are no molecular biomarkers to accurately predict disease progression (Soloway, 2013).

As for many other cancers, also for BC there is an established variation of individual susceptibility that may be modulated by interaction of environmental exposures and genetic factors. Biologic variability may occur at any stage of carcinogenesis; therefore, variation in inter-individual susceptibility poses a challenge in quantitative human risk assessment and warrants testing and validation of biomarkers that allow accurate identification of high-risk individuals. Evidence that cytogenetic biomarkers are positively correlated with cancer risk has been strongly validated in both cohort and nested case-control studies, leading to the conclusion that chromosome aberrations are a relevant marker of cancer risk (Bonassi et al, 2004), which reflects the outcome of both the genotoxic effects of carcinogens and the genetic host susceptibility. The cytokinesis-block micronucleus $(\mathrm{CBMN})$ assay is a relatively fast and easy technique extensively used in molecular epidemiology and cytogenetics. The assay is applied to evaluate the presence and the extent of chromosomal damage in populations exposed to genotoxic agents or in case of the presence of a susceptible genetic profile in several cell types, including newly divided peripheral blood mononuclear cells (PBMC; Bonassi et al, 2007). The measurement of micronucleus $(\mathrm{MN})$ frequency in PBMC has also been applied for the identification of dietary and genetic factors with a significant impact on genome stability. The high reliability and low cost of the CBMN technique has contributed to its success worldwide and to the adoption for in vitro and in vivo studies of genome damage (Bonassi et al, 2007). Similarly to other in vitro cytogenetic assays, there is a known inter- and intra-laboratory variability. However, there are still limited information on the effects of the laboratory method, subject lifestyle and the role of individual susceptibility on this variability. The long-term health significance of PBMC MN is also a major issue to be clarified. The International Human Micronucleus (HUMN) Project (www.humn.org) was created in this sense to coordinate worldwide research efforts aimed at using CBMN assays to study DNA damage in human populations and to establish standardised protocols so that data comparisons can be made more reliably across laboratories and countries (Fenech et al, 2011a).

The origin of MN is from whole chromosomes not included in the main daughter nuclei or from chromosome fragments that are lost during nuclear division. In dividing cells, the formation of $\mathrm{MN}$ derives from chromosome malsegregation due to mitotic malfunction or from unrepaired/misrepaired DNA lesions that generate chromosome breakage. The events described may be induced by several factors including oxidative stress, exposure to clastogens or aneugens, various genetic defects involving malfunctions of the cell cycle checkpoints and/or DNA repair, as well as deficiencies of nutrients important as cofactors for the metabolism of DNA and for the machinery of chromosome segregation (Fenech, 2007). Therefore, the CBMN assay can be considered a possible test to evaluate the level of DNA damage in the cells.
In the present study, we evaluated whether $\mathrm{MN}$ frequency as detected by the CBMN assay can be used as a potential molecular biomarker to identify individuals with increased risk of $\mathrm{BC}$, recurrence or progression in a large hospital-based case-control study (158 cases and 158 controls matched for gender (all males), age and smoking habits). The assay was performed on cryopreserved PBMC. Additionally, the distribution of genotypes of a large number of polymorphisms in DNA repair genes among cases (NMIBC) and controls and their associations with the frequencies of the analysed CBMN end points were investigated.

\section{MATERIALS AND METHODS}

Study population. The study population included newly diagnosed, histologically confirmed cases of BC included in the Turin Bladder Cancer Study (Sacerdote et al, 2013; Russo et al, 2014). Controls were men recruited during the same period as cases in random fashion from patients treated at the same urology departments for non-neoplastic disease or from patients treated at the medical and surgical departments for various problems (hernias, vasculopathies, diabetes, heart failure, asthma or other benign diseases). Detailed description of the study population is given in the Supplementary Materials and Methods. All subjects were informed and provided written informed consent according to the Helsinki declaration. The design of the study was approved by the local Ethics Committees.

Isolation and storing of lymphocytes. The isolation and storing of lymphocytes was described in Turinetto et al (2016). A more detailed description of the process is given in the Supplementary Materials and Methods.

Cytokinesis-block micronucleus assay. Cryopreserved PBMC from 158 cases (collected before treatment) and 158 controls matched by age ( \pm 1 year) and smoking habits, were selected from the Turin Bladder Cancer Study collection and processed for the CBMN assay.

Cell lymphocytes cultures were set up according to Zijno et al (2007). A detailed description of the assay is given in the Supplementary Materials and Methods. For each blood sample at least two cultures were set up in round-bottomed tissue cultures tubes. For each experiment 7-8 samples were processed.

For each subject, 1000 binucleated cells were scored from untreated cultures (500 cells from each of two cultures). Scoring of binucleated cells with MN, nucleoplasmic bridges (NPB) and nuclear buds (NBUD) was performed by two independent scorers following the criteria developed by Fenech et al (2007). Cell proliferation was evaluated determining the nuclear division index in 500 cells. Nuclear division index was calculated as follows: $(\mathrm{M} 1+2 \mathrm{M} 2+3 \mathrm{M} 3+4 \mathrm{M} 4) / \mathrm{N}$, where M1-M4 represent the number of cells with 1-4 nuclei respectively, and $N$ is the total number of viable cells scored.

Genotyping and quality controls. DNA was isolated from PBMC with the Qiagen DNeasy blood and tissue kit (Qiagen, Milan, Italy) according to the manufacturer's protocol.

Whole-genome genotyping was performed on an Illumina HumanOmniExpressExome-8 v1.2 (containing 964193 single nucleotide polymorphisms (SNPs)) for 306 subjects. Genotypes were assessed by GenomeStudio V2011.1 (Illumina, San Diego, CA, USA).

A cut-off for a genotyping call rate of 0.90 was set, leading to the exclusion of three study subjects. The identity by descent estimation was used to check relatedness among subjects ( $R$ 3.0.3, SNPRelate package). Subjects with kinship coefficient $>0.0625$ (two couples) were considered consanguineous and excluded (one per couple) from further analyses. Population 
structure was investigated through Principal Component Analysis: two outlier subjects were found and then removed, leaving 299 subjects (152 cases and 147 controls).

SNPs having $>5 \%$ missing genotypes $(n=7854)$, deviating from Hardy-Weinberg equilibrium $(P<0.0001, n=378)$ or with minor allele frequency $<5 \%(n=339,031)$ were excluded from the analysis, for a final study data set of 616454 SNPs. From 5412 SNPs in DNA repair genes present in the Illumina HumanOmniExpressExome-8 v1.2 BeadChip (http://sciencepark.mdanderson.org/ labs/wood/dna_repair_genes.html for the complete list of genes involved in different DNA repair pathways), 1457 passed the above described filters. Among them, 783 were selected after linkage disequilibrium analysis ( $\mathrm{R}$ 3.0.3, SNPRelate package, linkage disequilibrium threshold $\geqslant 0.8)$ and analysed for their distribution among cases and controls and for their potential association with CBMN frequencies.

Statistical analysis. All the analyses were performed with the open source R (R 3.1.0). The influence of possible explicative variables on the frequency of MN, NBUD and NPB was evaluated by multivariate analysis and/or non-parametric statistical hypothesis test, since variables did not follow a normal distribution (by Shapiro-Wilk normality test).

The Wilcoxon rank sum test was applied to compare the distribution of MN, NBUD and NPB between groups. Correlation analysis and Kruskal-Wallis rank sum test were also performed to estimate associations among independent variables (smoking habits, age, batch effect, etc).

Overall survival was evaluated calculating the time (in months) between the date of $\mathrm{BC}$ diagnosis and the date of death or follow up termination as the end point for each patient. Event-free survival was calculated as the time (in months) between the date of $\mathrm{BC}$ diagnosis until date of relapse, death or censorship, whichever came first. The relative risk of death or of recurrence/progression against each of the $3 \mathrm{CBMN}$ end points was estimated as hazard ratios using unadjusted Cox regression (R 3.0.3, Survival package). $\mathrm{MN}, \mathrm{NBUD}$ and NPB were all considered continuous or categorical; multivariate survival analyses were adjusted for matching variables, risk category and therapy for the whole group of patients. The prognostic role of CBMN end points on survival was also evaluated using Kaplan Meier curves and log-rank test. In the best fitted model survival analyses, hazard ratios were calculated by multivariate Cox regression, satisfying their proportional hazards $(\mathrm{PH})$ assumptions.

The distribution of genotypes of selected DNA repair variants among NMIBC cases and controls was evaluated in two steps, first by $\chi^{2}$ Test followed by regression analysis, adjusting for age and smoking habits.

The genotype influence on the frequency of micronucleated per 1000 binucleated cells was assessed by Kruskal-Wallis rank sum test only on NMIBC and in the same way as described above and then confirmed by regression analysis, adjusted for the same match variables.

Finally, different prediction models were built to evaluate the diagnostic power of investigated markers: (1) a model including age and smoking status (model A); (2) model A with the additional predictor SNPs with different genotype frequencies among cases and controls (model B); (3) model $\mathrm{B}$ with the inclusion of $\mathrm{MN}$ frequencies (model C). Discrimination analysis was conducted comparing the area under receiver operating characteristic (ROC) curve of the three nested models by the DeLong's test (pROC package).

\section{RESULTS}

Study population. The study included PBMC from 158 cases and 158 controls matched by age and smoking habits. For 10 controls and six cases, technical problems were encountered (i.e., slides were not scorable or the number of counted binucleated cells was not sufficient). Since no additional aliquots of cryopreserved PBMC were available these subjects were excluded from the analysis. Finally, 152 newly diagnosed, previously untreated males BC patients and 148 control subjects were included in the study. The characteristics of the whole cohort are summarised in Table 1. For 136 patients, tumours were classified as NMIBC $(T<2)$, whereas 16 patients were MIBC $(\mathrm{T} \geqslant 2)$. Forty-one cases had grade G1 cancer, whereas 64 and 47 had G2 and G3 grade, respectively. Fifty-four cases were classified as high-risk, 45 as intermediate and 37 as low-risk.

CBMN end points at diagnosis. The $3 \mathrm{CBMN}$ end points analysed, MN, NBUD and NPB, were not normally distributed $(P=6.10 \times 10 \mathrm{e}-09, \quad P=3.40 \times 10 \mathrm{e}-13 \quad$ and $\quad P<2.20 \times 10 \mathrm{e}-16$, respectively), therefore non-parametric tests were employed to verify differences among groups. Cytostasis, a biomarker of cell proliferation and mitogen responsiveness, was assessed by the nuclear division index via the ratio of mono-, bi- and multinucleated cells as described by Fenech (2007). No differences among scorers and batches were observed (data not shown).

Overall, cases had a mean $\mathrm{MN} \pm$ standard deviation (s.d.) frequency of $9.51 \pm 4.73$ compared with $7.73 \pm 3.91$ of controls. The mean NBUD \pm s.d. frequency in cases was $5.06 \pm 3.36$ compared with $3.99 \pm 2.44$ of controls. MN and NBUD frequencies were significantly higher in $\mathrm{BC}$ cases than in controls (Wilcoxon rank sum test, $P=0.001$ and $P=0.006$, respectively; Table 2, Figure $1 \mathrm{~A}$ and $\mathrm{B}$ ). When stratifying for the type of tumour and analysing only NMIBC, the differences in $\mathrm{MN}$ and NBUD frequencies among cases and controls were even more significant $(P=0.0005$ and $P=0.002$, respectively; Table 2, Figure $1 C$ and D). For MIBC the MN frequency trend was similar although results were not statistically significant. No differences in CBMN end points were observed after stratification for grade, tumour stage, risk class or number of recurrences (data not shown).

In a logistic regression model adjusted for age and smoking similar results were obtained for $\mathrm{MN}$ and NBUD frequencies (Table 3). In particular, for each increase of one unit in the MN frequency a 1.11 increase of risk of developing $\mathrm{BC}$ (all cases vs controls) and a 1.12 for NMIBC cases were observed. Similar results were observed when testing NBUD frequencies (1.14 and 1.16 increase of risk, respectively).

MN, NBUD and NPB correlated each other but they did not correlate with smoking or age (data not shown). A significant decreased frequency of MN was found in current smokers when compared with never smokers both when considering all subjects (adjusted model for age and case-control status, $P=0.03$ ) or only cases (adjusted model for age, $P=0.05$ ). BC cases showed higher $\mathrm{MN}$ frequencies in all subgroups with different smoking habits, though only former smokers showed significant differences in $\mathrm{MN}$ and NBUD levels between cases and controls $(P=0.003$ and $P=0.009$, respectively; Supplementary Figure 1A and B); similarly, when considering only NMIBCs (for $\mathrm{MN}$ in former smokers: $P=0.001$; for NBUD in current and former smokers: $P=0.04$ and $P=0.004$, respectively; Supplementary Figure $1 \mathrm{C}$ and D). When smokers were stratified in heavy, moderate and light smokers according to their consume of cigarettes, the observed trends did not change. Light smokers had a slight, although not statistically significant, increase of $\mathrm{MN}$ frequency when compared with heavy smokers or to non-smokers (never and former smokers together; data not shown but available upon request).

CBMN assay in relation to clinical outcome. The information of patient follow up is briefly reported in Table 1. Most patients (105) were treated with either chemotherapy and/or Bacillus CalmetteGuerin (BCG) therapy. In total, 55 subjects recurred and 24 died. The mean (median) overall survival and event-free survival for 
Table 1. Baseline characteristics of the BC patients and information at follow up

\begin{tabular}{|c|c|c|}
\hline Covariates & Cases (\%) & Controls (\%) \\
\hline$N$ & 152 & 148 \\
\hline NMIBC & $136(89.5)$ & - \\
\hline MIBC & $16(10.5)$ & - \\
\hline $\begin{array}{l}\text { Age (years) } \\
\text { Mean } \pm \text { s.d. } \\
\text { Range }\end{array}$ & $\begin{array}{l}62.3 \pm 7.9 \\
40.0-74.1\end{array}$ & $\begin{array}{l}62.8 \pm 8.7 \\
40.3-74.9\end{array}$ \\
\hline $\begin{array}{l}\text { Smoking Status } \\
\text { Never } \\
\text { Former } \\
\text { Current }\end{array}$ & $\begin{array}{l}21(13.8) \\
94(61.8) \\
37(24.4)\end{array}$ & $\begin{array}{l}24(16.2) \\
90(60.8) \\
34(23.0)\end{array}$ \\
\hline $\begin{array}{c}\text { T stage } \mathbf{a}^{\mathbf{a}} \\
\text { Ta } \\
\text { T1 } \\
\text { T2 } \\
\text { T3 } \\
\text { T4 } \\
\text { Tis } \\
\text { Tx }\end{array}$ & $\begin{array}{c}84(55.3) \\
46(30.3) \\
14(9.2) \\
1(0.7) \\
1(0.7) \\
3(1.9) \\
3(1.9)\end{array}$ & $\begin{array}{l}- \\
- \\
- \\
- \\
- \\
- \\
-\end{array}$ \\
\hline $\begin{array}{l}\text { Grading }(1973)^{a} \\
\text { G1 } \\
\text { G2 } \\
\text { G3 }\end{array}$ & $\begin{array}{l}41(27.0) \\
64(42.1) \\
47(30.9)\end{array}$ & $\begin{array}{l}- \\
- \\
-\end{array}$ \\
\hline $\begin{array}{l}\text { Grading (2004) } \\
\text { Non-high grade } \\
\text { High grade }\end{array}$ & $\begin{array}{l}77(50.7) \\
75(49.3)\end{array}$ & - \\
\hline $\begin{array}{l}\text { Risk }^{\text {a }} \\
\text { Low-risk } \\
\text { Intermediate Risk } \\
\text { High-risk } \\
\text { Muscle invasive }\end{array}$ & $\begin{array}{l}37(24.4) \\
45(29.6) \\
54(35.5) \\
16(10.5)\end{array}$ & $\begin{array}{l}- \\
- \\
-\end{array}$ \\
\hline $\begin{array}{l}\text { Recurrence } \\
\text { No } \\
\text { Yes }\end{array}$ & $\begin{array}{l}97(63.8) \\
55(36.2)\end{array}$ & - \\
\hline $\begin{array}{l}\text { Number of recurrences } \\
1 \\
2 \\
\geqslant 3\end{array}$ & $\begin{array}{c}35(63.6) \\
15(27.3) \\
5(9.1)\end{array}$ & $\begin{array}{l}- \\
- \\
-\end{array}$ \\
\hline $\begin{array}{l}\text { Progression } \\
\text { No } \\
\text { Yes }\end{array}$ & $\begin{array}{c}146(96.1) \\
6(3.9)\end{array}$ & - \\
\hline $\begin{array}{l}\text { Therapy } \\
\text { No } \\
\text { Yes }\end{array}$ & $\begin{array}{r}47(30.9) \\
105(69.1)\end{array}$ & - \\
\hline $\begin{array}{l}\text { Cystectomy } \\
\text { No } \\
\text { Yes }\end{array}$ & $\begin{array}{r}125(82.2) \\
27(17.8)\end{array}$ & - \\
\hline $\begin{array}{l}\text { BC patient DiacriticalGrave status at } \\
\text { follow up } \\
\text { Alive } \\
\text { Died } \\
\text { Of which for BC }\end{array}$ & $\begin{array}{c}128(84.2) \\
24(15.8) \\
11\end{array}$ & - \\
\hline
\end{tabular}

Abbreviations: $\mathrm{BC}=$ bladder cancer; $\mathrm{MIBC}=$ muscle-invasive bladder cancer; $\mathrm{NMIBC}=$ non-muscle invasive bladder cancer.

${ }^{a_{F}}$ or reference see: (1) Babjuk et al, 2013; (2) Cheng et al, 2000; (3) Montironi and LopezBeltran, 2005.

patients were 54.5 (50.6) and 41.8 (35.7) months, respectively. Age and risk classification (Babjuk et al, 2013; Witjes et al, 2014) were associated with overall survival (but not event-free survival) in the preliminary univariate assessment of covariates.

No significant associations with survival or recurrence risk were observed for any of the CBMN end points analysed (data not shown).

Genotype distribution in relation to case-control status and $\mathrm{MN}$ frequencies. A total of 783 SNPs in genes belonging to different pathways of DNA repair that remained after the quality control were analysed only in the largest group of NMIBC patients $(n=132)$ and in controls $(n=147)$. Genotypes frequencies of eight SNPs were differentially distributed between NMIBC and controls $\left(P<0.01 ; \chi^{2}\right.$ test $)$ in a linear model adjusted for age and smoking habits (Supplementary Table 1). In particular, an increased risk for NMIBC cases was observed in carriers of the AG or GG genotype for rs804267 in NEIL2 ( $P=0.02$ and $P=0.001$, respectively) when compared with the AA genotype. A similar trend was observed for carriers of the AC or CC genotypes for NEIL3 rs6817959 $(P=0.0006$ and $P=0.01$, respectively) when compared with the AA genotype. Conversely, having one or two variant alleles for rs7311151 in RAD52 appeared to be protective when compared with the reference genotype AA $(P=0.004$ for the heterozygous and $P=0.03$ for the homozygous variant GG). The same observations were derived for carriers of TC and CC genotypes for FANCL rs11903456 $(P=0.03$ for both genotypes when compared with the wild type).

Ten SNPs were associated with significantly different MN frequencies according to the genotype stratification in NMIBC patients $(P<0.01$; Kruskall-Wallis rank sum test; Supplementary Table 2). Five of these SNPs were in genes involved in homologous recombination pathway (Supplementary Figure 2). No differences in $\mathrm{MN}$ frequencies according to a particular genotype were observed among controls for these 10 SNPs (see Supplementary Table 2). Interestingly, for RAD51B rs2257127, the MN frequencies in patients decreased according to the presence of 0,1 or 2 variant alleles, whereas in controls this trend was the opposite, though significant only when comparing the homozygous subjects. Similar considerations could be done for rs 1866074 in TDG, but in this case $\mathrm{MN}$ frequency increased in relation to the number of variant alleles. Notably, the observed differences were confirmed when applying an additive model of inheritance of the minor allele (data not shown). In a linear model controlling for age and smoking status, NMIBC patients carrying the TC or the CC genotypes of $X P C$ rs 2470458 showed a significant decrease of 2.29 and 4.78 units of $\mathrm{MN}$, respectively, when compared with the most frequent TT genotype $(P=0.01$ and $P=0.03)$. An opposite trend was found for rs976080 in ERCC8 (increase of 3.31 MN units for CA carriers when compared with the reference; $P=0.002$ ). For rs 1866074 in $T D G$, there was an increase in the frequencies of $\mathrm{MN}$ in carriers of AG and GG genotypes when compared with carriers of the reference genotype AA (increase of 2.43 and 4.05 units of $\mathrm{MN}$; $P=0.02$ and $P=0.001$, respectively; Figure 2).

Other SNPs significantly modulating NBUD and NPB frequencies are reported in Supplementary Table 3.

To evaluate the improvement in the performance of NMIBC case prediction when including genotype of DNA repair genes and MN frequencies, we analysed three nested models: model $\mathrm{A}=$ including age and smoking status; model $\mathrm{B}=$ model $\mathrm{A}+\mathrm{rs} 804267+$ rs6817959 + rs11903456 + rs7311151; model $\mathrm{C}=$ model $\mathrm{B}+\mathrm{MN}$ frequencies. Comparing the area under ROC curve of the three models there was a statistically significant improvement in discrimination of NMIBC: in particular the area under ROC curves were $0.55,0.75$ and 0.79 for model $\mathrm{A}, \mathrm{B}$ and $\mathrm{C}$, respectively (model A vs model B: DeLong's $P=2.80 \times 10 \mathrm{e}-06$; model $\mathrm{B}$ vs model C: DeLong's $P=0.02$; Figure 3 ).

\section{DISCUSSION}

In the present study, the main result was an increased frequency of $\mathrm{MN}$ and NBUD in cryopreserved lymphocytes of BC cases assessed at diagnosis compared with controls, either considering all cases or, with an even more marked difference, the subgroup of NMIBC. 
Several studies report an increased baseline frequency of $\mathrm{MN}$ and other CBMN end points in PBMC of cancer patients (reviewed by Bonassi et al, 2011), confirming the presence of a high genetic instability in cancer. The majority of studies reported the presence of increased $\mathrm{MN}$ frequencies in individuals with cancer or with preneoplastic lesions. The number of studies performed on PBMC is quite high (8 studies on breast, 6 on lung, 2 on gastroenteric cancers and 13 on other malignancies). However, all these studies were mostly based on a small sample size. The only exceptions are represented by the study of Duffaud et al (1999), performed on PBMC from 197 controls and 57 head-and-neck cancer patients, and the one of ElZein et al (2006), on lymphocytes from 139 lung cancer cases and 130 controls. Thus, our study is the largest study so far on BC patients.
The CBMN assay measures chromosomal DNA damage, cytostasis and cytotoxicity events in the cell population (Fenech, 2007). It is generally accepted that events of genetic damage such as $\mathrm{MN}$ and NBUD may represent a reflection of misrepaired DNA breaks, dysregulation on telomere length as well as malfunctions in the mitotic machinery and DNA amplification (Fenech et al, 2011b). An increase in MN frequency may be considered a biomarker of chromosome loss and/or breakage, whereas other anomalies such as NBUD are biomarkers of gene amplification and/or removal of unresolved DNA repair complexes (Bonassi et al, 2011). In cancer, an increase of various manifestations of chromosomal instability is often observed. Assuming that the induction of chromosomal damage employs similar mechanisms in

Table 2. Frequencies of analysed end points by the CBMN assay in peripheral blood mononuclear cells of BC cases and healthy controls

\begin{tabular}{|l|c|c|c|c|c|c|c|c|}
\hline \multicolumn{2}{|c|}{} & Controls & All BC Cases & $P^{\mathrm{b}}$ & NMIBC & $P^{\mathrm{b}}$ & MIBC & $P^{\mathrm{b}}$ \\
\hline Frequencies & a & $N$ & 148 & 152 & & 136 & & 16 \\
\hline MN & Mean \pm s.d. & $7.73 \pm 3.91$ & $9.51 \pm 4.73$ & 0.001 & $9.68 \pm 4.77$ & 0.0005 & $8.06 \pm 4.24$ & 0.91 \\
\hline NPB & Mean \pm s.d. & $0.88 \pm 0.90$ & $0.98 \pm 1.03$ & 0.61 & $0.99 \pm 1.03$ & 0.55 & $0.88 \pm 1.09$ & 0.85 \\
\hline NBUD & Mean \pm s.d. & $3.99 \pm 2.44$ & $5.06 \pm 3.36$ & 0.006 & $5.20 \pm 3.41$ & 0.002 & $3.87 \pm 2.69$ & 0.65 \\
\hline
\end{tabular}

Abbreviations: $\mathrm{BC}=$ bladder cancer; $\mathrm{MIBC}=$ muscle-invasive bladder cancer; $\mathrm{MN}=$ micronuclei; $\mathrm{NBUD}=$ nuclear buds; $\mathrm{NMIBC}=$ non-muscle invasive bladder cancer; $\mathrm{NPB}=$ nucleoplasmic bridge. Significant results in bold.

${ }^{a}$ Mean frequencies for 1000 binucleated cells.

bilcoxon Rank sum test.

A

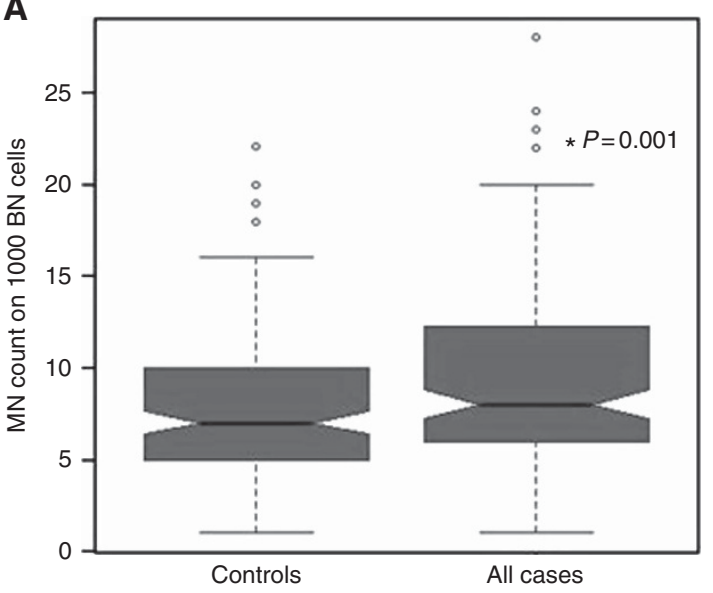

C

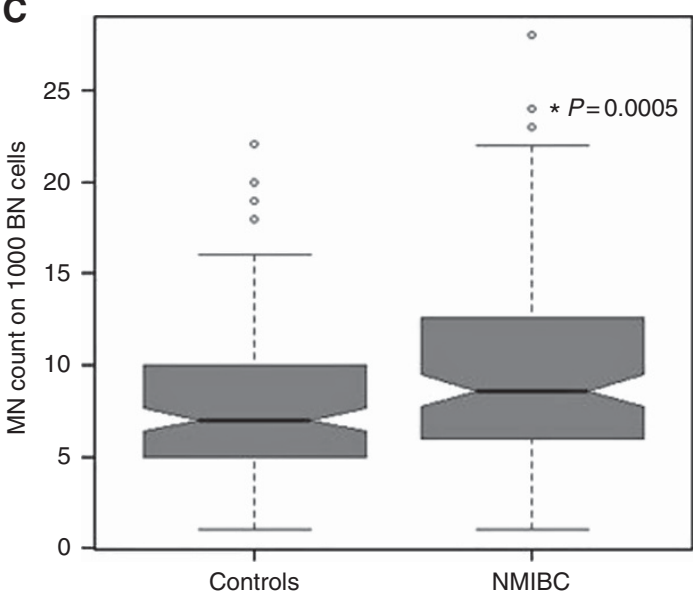

B

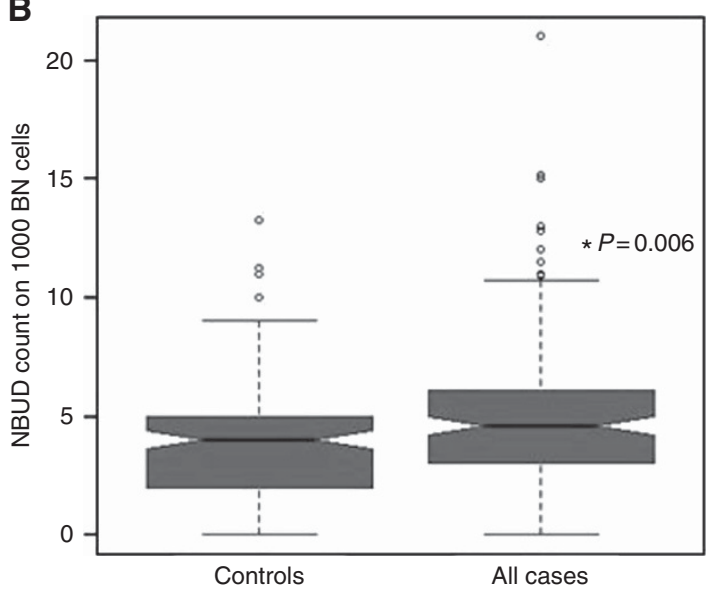

D

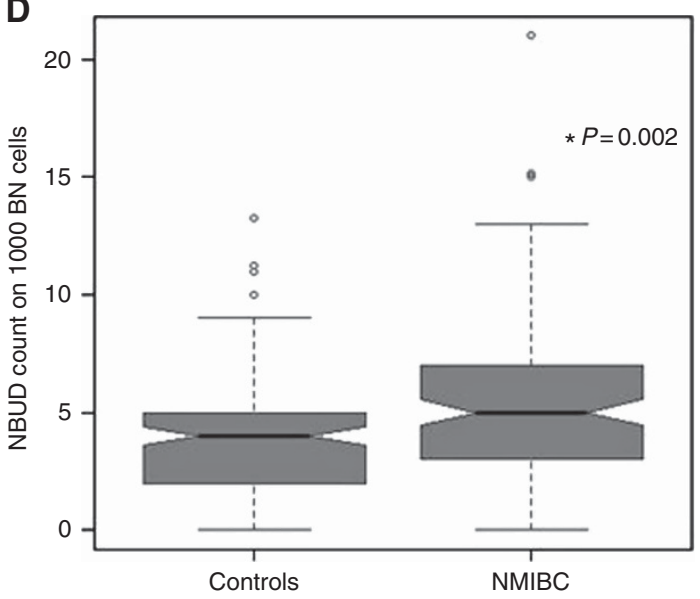

Figure 1. Box plot for comparison of MN and NBUD frequencies in different study groups: $M N$ frequencies in (A) BC cases vs controls and (C) in NMIBC cases vs controls; NBUD frequencies in (B) BC cases vs controls and (D) in NMIBC cases vs controls. 
different tissues, the levels of damage measured in lymphocytes and other surrogate tissues may reflect those present in the cancerprone tissues (Bonassi et al, 2011; Slyskova et al, 2012a).

Constitutive DNA damage in cells can be considered a predictive biomarker indicating a potential increase in cancer risk. The thresholds of tolerable DNA/chromosomal damage are known for small eukaryotic organisms such as Saccharomyces cerevisiae, but little is known for human cells (Khanna, 2015). An increase in

Table 3. Logistic regression model of analysed end points by the CBMN assay for: (A) BC vs controls; (B) NMIBC vs controls; (C) MIBC vs controls

\begin{tabular}{|c|c|c|c|}
\hline & Coefficients & s.e. & $P^{a}$ \\
\hline \multicolumn{4}{|l|}{$\mathrm{MN}$} \\
\hline $\begin{array}{l}\text { BC vs controls } \\
\text { NMIBC vs controls } \\
\text { MIBC vs controls }\end{array}$ & $\begin{array}{l}0.104 \\
0.114 \\
0.011\end{array}$ & $\begin{array}{l}0.029 \\
0.030 \\
0.069\end{array}$ & $\begin{array}{c}<0.01 \\
<0.01 \\
0.87\end{array}$ \\
\hline \multicolumn{4}{|l|}{ NPB } \\
\hline $\begin{array}{l}\text { BC vs controls } \\
\text { NMIBC vs controls } \\
\text { MIBC vs controls }\end{array}$ & $\begin{array}{r}0.115 \\
0.130 \\
-0.016\end{array}$ & $\begin{array}{l}0.121 \\
0.125 \\
0.292\end{array}$ & $\begin{array}{l}0.34 \\
0.30 \\
0.96\end{array}$ \\
\hline \multicolumn{4}{|l|}{ NBUD } \\
\hline $\begin{array}{l}\text { BC vs controls } \\
\text { NMIBC vs controls } \\
\text { MIBC vs controls }\end{array}$ & $\begin{array}{r}0.132 \\
0.148 \\
-0.037\end{array}$ & $\begin{array}{l}0.043 \\
0.045 \\
0.112\end{array}$ & $\begin{array}{c}<0.01 \\
<0.01 \\
0.74\end{array}$ \\
\hline \multicolumn{4}{|c|}{$\begin{array}{l}\text { Abbreviations: } \mathrm{BC}=\text { bladder cancer; } \mathrm{MIBC}=\text { muscle-invasive bladder cancer; } \mathrm{MN}=\text { micronuclei } \\
\text { frequencies; } \mathrm{NBUD}=\text { nuclear buds frequencies; } \mathrm{NMIBC}=\text { Non-muscle invasive bladder cancer; } \\
\mathrm{NPB}=\text { nucleoplasmic bridge frequencies; s.e. = standard error. Significant results in bold. } \\
\text { a Adjusted for age and smoking. }\end{array}$} \\
\hline
\end{tabular}

MN frequency in PBMC of BC cases when compared with controls could be interpreted as an altered status in the DNA damage repair system or reflects an unknown past exposure. These lead to the accumulation of chromosomal damage promoting malignant transformation. However, there is no common agreement on that and an altered DNA repair system could be also a direct effect in the organism of the presence of the tumour (Vafa et al, 2002). A better understanding of the level of systemic DNA damage in cancer patients may help in a more precise use of therapeutic intervention. For example, a better definition for the minimum threshold of DNA/chromosomal damage that kills tumour cells directly or reactivates mechanisms of tumour-suppression can help in choosing a more effective chemo- or radiotherapy dosage (Khanna, 2015).

Several factors may modulate the MN formation and frequency. Lifestyle habits (smoking, alcohol, vitamin intake) and host factors (age, gender) are among them, as well as genetic polymorphisms and exposure to specific mutagen agents (Luzhna et al, 2013). Notably, we observed a significant decrease in MN frequency in current smokers when compared with non-smokers (both considering all subjects and only cases). This is in line with previous investigations on the impact of smoking on MN levels, in which the MN rates are higher in non-smokers than in smokers (reviewed by Nersesyan et al (2014)). The reduction of MN levels in smokers reported in literature is usually present only in light and moderate smokers, whereas heavy smokers have higher levels of MN when also occupational exposure is taken into account (Bonassi et al, 2003). In our study we did not observe this phenomenon after categorisation according to the consume of cigarettes. This is probably due to the fact that the number of
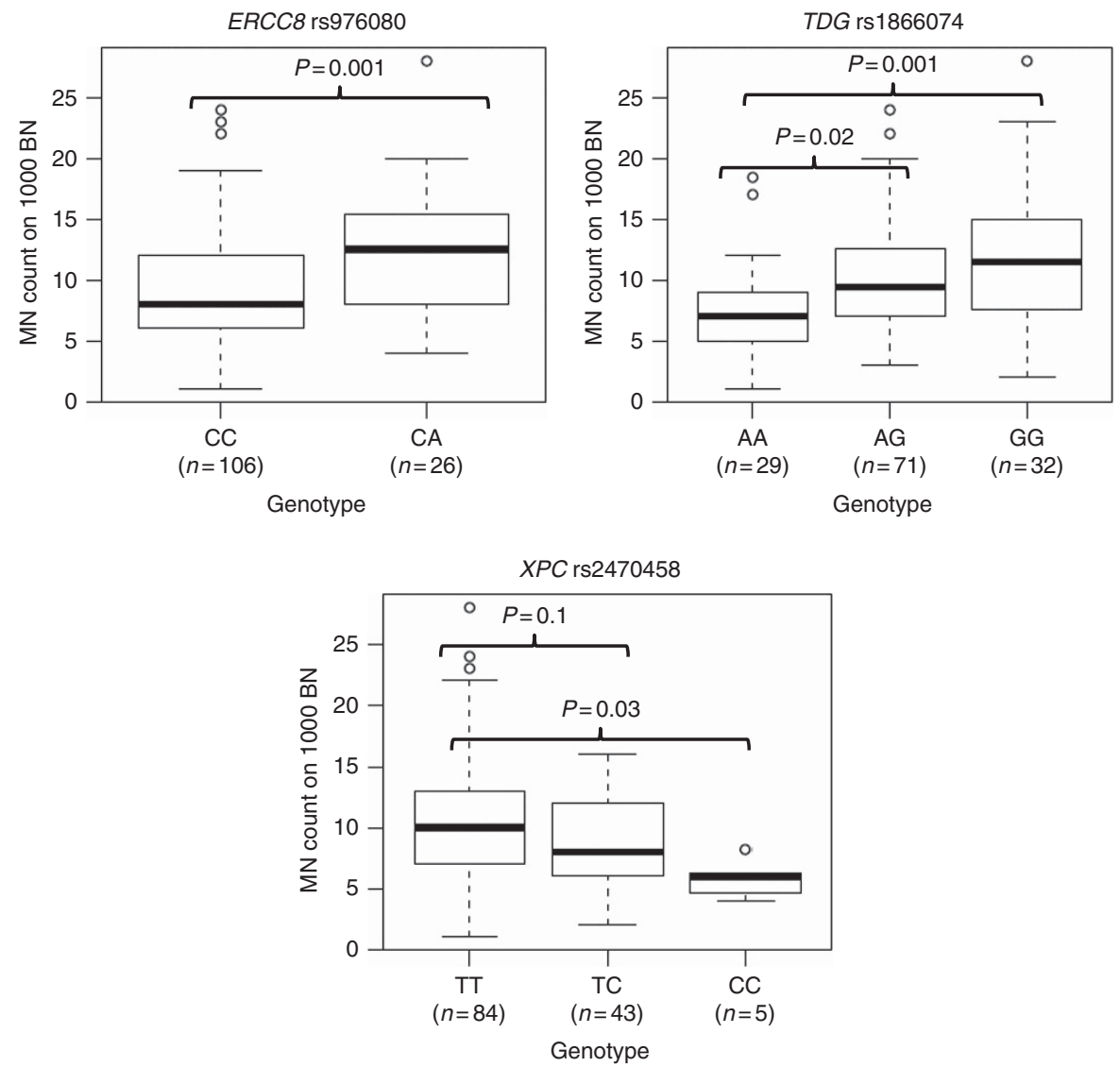

Figure 2. MN frequencies in NMIBC patients $(n=132)$ according to genotype distribution of selected SNPs in DNA repair genes (Kruskal-Wallis $P<0.01$ ). 


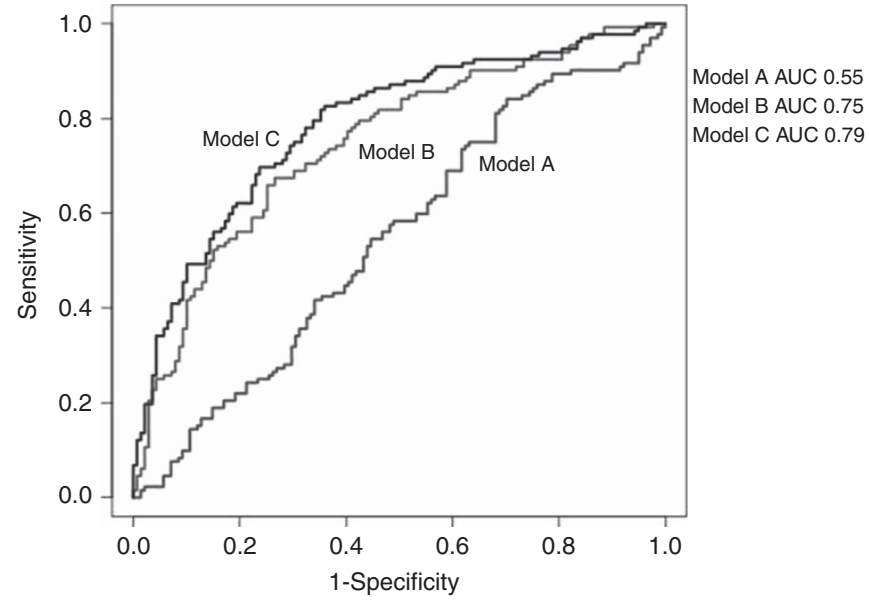

Figure 3. ROC curve analysis for discrimination of NMIBC. Model A investigated the risk reached by adding age and smoking habit; model $\mathrm{B}$ included also the SNPs differentially distributed among cases and controls (model A + rs804267 + rs6817959 + rs11903456 + rs7311151); model C included model B and MN frequencies.

smokers is too small to observe an effect of smoke on $\mathrm{MN}$ frequencies as reported in other studies. Interestingly, smoking or formerly smoking BC patients had still higher levels of chromosomal damage than controls and the observed effect of smoking could be due to a constitutively activated antioxidant response system or an active DNA repair. The question on the effect of smoking on $\mathrm{MN}$ frequencies is still open and results in literature are controversial (Nersesyan et al, 2014).

Knowing a patient's basal genetic background and consequently the individual DNA repair capacity is important for predicting BC risk. Genetic variants in DNA repair genes that could modify BC risk and prognosis has already been identified in various studies, including polymorphisms in XRCC1, XRCC4, XPF, XPD and XPC (Wang et al, 2010; He et al, 2013; Peng et al, 2014). Among the eight SNPs significantly associated with NMIBC risk in the present study, NEIL2 rs804267 has been associated in another study with risk of recurrence/progression in 421 NMIBC patients, particularly in those receiving BCG therapy (Wei et al, 2012). Conversely, rs25487 in XRCC1 was associated with decreased risk of BC in the present study and in a previous one performed on 227 Chinese BC patients and 260 controls ( $\mathrm{Zhu}$ et al, 2016). The functional significance of XPC rs2470458 is still unclear. XPC rs2470458 has been indicated as an important and independent predictor for survival of melanoma patients (Li et al, 2013). In a previous study, the presence of the variant allele of rs2228000 (in linkage disequilibrium with rs2470458), which causes a Val499Ala amino acid change, modulated expression levels of $X P C, X P B$ and $X P D$ genes in colorectal cancer patients (Slyskova et al, 2012b). In particular, rs2228000 is well-known to contribute to the susceptibility to BC in Caucasian populations (Wang et al, 2014). Finally, BC patients carrying the GG genotype of rs1866074 resulted at decreased risk of disease progression (Wei et al, 2012). Although the effect of a single SNP on BC risk may be limited, the combined effect of several SNPs in the same or different genes could be more significant. Interestingly, tagging SNPs selected across the entire coding and putative regulatory regions of ERCC8 (known as CSA) were associated with mutagen sensitivity induced by BPDE in 276 cancer-free smokers as measured with the comet assay (Leng et al, 2008).

In a review by Fenech and collaborators, a detailed nutrientgene interaction model involving various molecular mechanisms has been reported. In this model, the interaction between a specific polymorphism in $M T H F R$, folate and riboflavin deficiency in the diet lead to MN, NPB and NBUD formation as a consequence of derived chromosomal instability through several molecular mechanisms. Analogous models could be plausibly extended to other pathways such as DNA repair (Fenech et al, 2011b). $\mathrm{MN}$ formation derives from genetic defects in cell cycle checkpoints and/or DNA repair genes, therefore, genetic variations in such genes may also affect the levels of chromosome damage by ultimately modulating the individual DNA repair activity (Iarmarcovai et al, 2008). Specific genotypes of polymorphisms in DNA repair genes such as $X P D, X R C C 1$ and $X R C C 3$ were previously associated with increased $\mathrm{MN}$ frequencies in workers exposed to ionising radiation (Angelini et al, 2005). In the present study, we evaluated $\mathrm{MN}$ frequencies in NMIBC cases in relation to a large number of polymorphisms in DNA repair genes, investigated at GWAS level. Among the 10 SNPs associated with different $\mathrm{MN}$ frequencies according to the genotype stratification, three of them (rs2470458 in XPC, rs1866074 in TDG and rs976080 in ERCC8) resulted in significant associations also in the linear model. For the polymorphism in XPC a decrease in the MN frequency was observed in variant allele carriers when compared with the reference genotypes. For TDG rs1866074, there was an increase in the frequencies of $\mathrm{MN}$ in carriers of $\mathrm{AG}$ and $\mathrm{GG}$ genotypes when compared with carriers of the reference genotype AA. A similar observation was done for carriers of the CA genotype in ERCC8 rs976080, although in the present study there were no AA homozygotes. It seems that the presence of a single A allele for this SNP is sufficient to have a significant increase in the $\mathrm{MN}$ frequency. Interestingly, among the 10 SNPs altering MN frequency in NMIBC there was an overrepresentation of polymorphisms in genes involved in the homologous recombination pathway (5 out of 10; XRCC3 rs861539, SHFM1 rs12704871, RAD51B rs2257127, PARP1 rs3754376 and rs1136410), which is supposed to be the main DNA repair pathway involved in the control of chromosome stability (Serra et al, 2013), and whose subtle inter-individual differences may be connected to altered MN frequencies.

We are aware of some weaknesses of the present study. The CBMN assay is a highly sensitive method to evaluate the action of genotoxic agents, which may trigger the cascade of events leading to $\mathrm{BC}$ onset. However, in a cross-sectional study like the present one, this test does not provide any insight as to whether the observed chromosomal damage is a cause or a consequence of some exposure/presence of the disease. Moreover, human lymphocytes are usually used for measuring genotoxic effects induced by various mutagens in human biomonitoring studies, but the sensitivity of $\mathrm{MN}$ end points may be limited by the repair of DNA damage during PHA-stimulated lymphocytes culture. On the other hand, previous studies have demonstrated that there are no differences in DNA damage and repair capacity between unstimulated and PHA-stimulated lymphocytes even after $72 \mathrm{~h}$ of culture (Bausinger and Speit, 2015).

A recent review reported all the studies applying the $\mathrm{MN}$ assay in urine-derived cells (UDC) as a diagnostic tool for BC detection and prognosis (Nersesyan et al, 2014). To our knowledge, only few studies investigated if the $\mathrm{MN}$ assay could be applied as a diagnostic tool to identify individuals who have BC (Arora et al, 2010; Sharma et al, 2012; de Castro Marcondes et al, 2014). The currently available data suggested that MN assays in UDC may be potentially a suitable diagnostic tool for detection of $\mathrm{BC}$ and for the surveillance of the patients (Nersesyan et al, 2014). The specificity and sensitivity of the assay on UDC has to be further validated in large studies. The available studies, in fact, are restricted to a small number of subjects ( $<50$ subjects) highlighting that for large studies it could be difficult to process a large number of fresh urine samples. Although urine could be potentially a better specimen for the study of $\mathrm{BC}$ risk rather than PBMC, it should be considered that the MN assay applied to UDC presents still some limitations. 
UDC extraction needs in fact to be performed on fresh urine to ensure viable cells. Moreover, the proportion of live cells extracted from urine is very low so sometimes it is not possible to score enough cells.

In theory, employing fresh blood is more advantageous from the practical point of view, since with small blood amounts it is possible to obtain good cells proliferation after mitogen stimulation. However, there are some drawbacks that limit its use in human cytogenetic studies. It is in fact quite difficult to process hundreds of samples in a short time as requested in large studies. Moreover, it has been demonstrated that to arrange the blood collection over a long-time interval may increase the experimental variability due to seasonal variation (Zijno et al, 2007). These limitations can potentially be overcome by employing cryopreserved cells. The use of these cells may allow a better study planning with a priori selection of subjects of interest and the possibility to data recovery in case of lost samples. Cryopreserved PBMC have been successfully used before for measuring endogenous DNA damage and/or DNA repair capacity by different assays (D’Errico et al, 1999; Chang et al, 2006), but also for MN analysis with cytokinesis-block (Zijno et al, 2007) bringing significant advantages in biomonitoring and for biomarkers research.

In conclusion, the observed increase in $\mathrm{MN}$ and NBUD frequencies in $\mathrm{BC}$ cases could be used to better estimate individual $\mathrm{BC}$ risk, including in the same model classical risk factors and DNA repair genetic susceptibility variants. Understanding the level of systemic chromosomal damage in cancer patients may also help in more precise therapeutic intervention.

\section{ACKNOWLEDGEMENTS}

We are very thankful to E Van Emburgh and B O'Brien Van Emburgh for their technical support and to all patients that participated with enthusiasm to the present study. This work was supported by the Human Genetics Foundation (HuGeF) and Compagnia di San Paolo Torino, Italy (to BP, CV, AA, AN, RC, PV and GM); by Fondazione Umberto Veronesi 'Post-doctoral fellowship Year 2014, 2015 and 2016' (BP recipient) and Grant 2013 (GM recipient); by Associazione Italiana per la Ricerca sul Cancro (Italian Association for Cancer Research)-IG 174646 (GM recipient) and 'Fondi MIUR Ricerca Locale di Ateneo (ex-60\%) 2015 (GM recipient).

\section{CONFLICT OF INTEREST}

The authors declare no conflict of interest.

\section{REFERENCES}

Angelini S, Kumar R, Carbone F, Maffei F, Forti GC, Violante FS, Lodi V, Curti S, Hemminki K, Hrelia P (2005) Micronuclei in humans induced by exposure to low level of ionizing radiation: influence of polymorphisms in DNA repair genes. Mutat Res 570(1): 105-117.

Arora SK, Dey P, Saikia UN (2010) Micronucleus in atypical urothelial cells. Diagn Cytopathol 38(11): 811-813.

Babjuk M, Burger M, Zigeuner R, Shariat SF, van Rhijn BW, Comperat E, Sylvester RJ, Kaasinen E, Bohle A, Palou Redorta J, Roupret M (2013) EAU guidelines on non-muscle-invasive urothelial carcinoma of the bladder: update 2013. Eur Urol 64(4): 639-653.

Bausinger J, Speit G (2015) DNA repair capacity of cultured human lymphocytes exposed to mutagens measured by the comet assay and array expression analysis. Mutagenesis 30(6): 811-820.

Bonassi S, El-Zein R, Bolognesi C, Fenech M (2011) Micronuclei frequency in peripheral blood lymphocytes and cancer risk: evidence from human studies. Mutagenesis 26(1): 93-100.
Bonassi S, Neri M, Lando C, Ceppi M, Lin YP, Chang WP, Holland N, Kirsch-Volders M, Zeiger E, Fenech M. HUMN collaborative group (2003) Effect of smoking habit on the frequency of micronuclei in human lymphocytes: results from the Human MicroNucleus project. Mutat Res (2003) 543(2): 155-166.

Bonassi S, Znaor A, Ceppi M, Lando C, Chang WP, Holland N, KirschVolders M, Zeiger E, Ban S, Barale R, Bigatti MP, Bolognesi C, CebulskaWasilewska A, Fabianova E, Fucic A, Hagmar L, Joksic G, Martelli A, Migliore L, Mirkova E, Scarfi MR, Zijno A, Norppa H, Fenech M (2007) An increased micronucleus frequency in peripheral blood lymphocytes predicts the risk of cancer in humans. Carcinogenesis 28(3): 625-631.

Bonassi S, Znaor A, Norppa H, Hagmar L (2004) Chromosomal aberrations and risk of cancer in humans: an epidemiologic perspective. Cytogenet Genome Res 104(1-4): 376-382.

Chang JL, Chen G, Lampe JW, Ulrich CM (2006) DNA damage and repair measurements from cryopreserved lymphocytes without cell culture-a reproducible assay for intervention studies. Environ Mol Mutagen 47(7): 503-508.

Cheng L, Weaver AL, Leibovich BC, Ramnani DM, Neumann RM, Scherer BG, Nehra A, Zincke H, Bostwick DG (2000) Predicting the survival of bladder carcinoma patients treated with radical cystectomy. Cancer 88(10): 2326-2332.

D’Errico M, Calcagnile A, Iavarone I, Sera F, Baliva G, Chinni LM, Corona R, Pasquini P, Dogliotti E (1999) Factors that influence the DNA repair capacity of normal and skin cancer-affected individuals. Cancer Epidemiol Biomarkers Prev 8(6): 553-559.

de Castro Marcondes JP, de Oliveira ML, Gontijo AM, de Camargo JL, Salvadori DM (2014) Genetic instability persists in non-neoplastic urothelial cells from patients with a history of urothelial cell carcinoma. PLoS One 9(1): e86162.

Dudek AM, Grotenhuis AJ, Vermeulen SH, Kiemeney LA, Verhaegh GW (2013) Urinary bladder cancer susceptibility markers. What do we know about functional mechanisms? Int J Mol Sci 14(6): 12346-12366.

Duffaud F, Orsiere T, Digue L, Villani P, Volot F, Favre R, Botta A (1999) Micronucleated lymphocyte rates from head-and-neck cancer patients. Mutat Res 439(2): 259-266.

El-Zein RA, Schabath MB, Etzel CJ, Lopez MS, Franklin JD, Spitz MR (2006) Cytokinesis-blocked micronucleus assay as a novel biomarker for lung cancer risk. Cancer Res 66(12): 6449-6456.

Fenech M (2007) Cytokinesis-block micronucleus cytome assay. Nat Protoc 2(5): 1084-1104.

Fenech M, Holland N, Zeiger E, Chang WP, Burgaz S, Thomas P, Bolognesi C, Knasmueller S, Kirsch-Volders M, Bonassi S (2011a) The HUMN and HUMNxL international collaboration projects on human micronucleus assays in lymphocytes and buccal cells-past, present and future. Mutagenesis 26(1): 239-245.

Fenech M, Kirsch-Volders M, Natarajan AT, Surralles J, Crott JW, Parry J, Norppa H, Eastmond DA, Tucker JD, Thomas P (2011b) Molecular mechanisms of micronucleus, nucleoplasmic bridge and nuclear bud formation in mammalian and human cells. Mutagenesis 26(1): 125-132.

Ferlay J, Soerjomataram I, Dikshit R, Eser S, Mathers C, Rebelo M, Parkin DM, Forman D, Bray F (2015) Cancer incidence and mortality worldwide: sources, methods and major patterns in GLOBOCAN 2012. Int J Cancer 136(5): E359-E386.

He J, Shi TY, Zhu ML, Wang MY, Li QX, Wei QY (2013) Associations of Lys939Gln and Ala499Val polymorphisms of the XPC gene with cancer susceptibility: a meta-analysis. Int J Cancer 133(8): 1765-1775.

Iarmarcovai G, Bonassi S, Botta A, Baan RA, Orsiere T (2008) Genetic polymorphisms and micronucleus formation: a review of the literature. Mutat Res 658(3): 215-233.

Khanna A (2015) DNA damage in cancer therapeutics: a boon or a curse? Cancer Res 75(11): 2133-2138.

Leng S, Bernauer A, Stidley CA, Picchi MA, Sheng X, Frasco MA, Van Den Berg D, Gilliland FD, Crowell RE, Belinsky SA (2008) Association between common genetic variation in Cockayne syndrome A and $\mathrm{B}$ genes and nucleotide excision repair capacity among smokers. Cancer Epidemiol Biomarkers Prev 17(8): 2062-2069.

Li C, Yin M, Wang LE, Amos CI, Zhu D, Lee JE, Gershenwald JE, Grimm EA, Wei Q (2013) Polymorphisms of nucleotide excision repair genes predict melanoma survival. J Invest Dermatol 133(7): 1813-1821.

Luzhna L, Kathiria P, Kovalchuk O (2013) Micronuclei in genotoxicity assessment: from genetics to epigenetics and beyond. Front Genet 4: 131. 
Matullo G, Naccarati A, Pardini B (2015) microRNA expression profiling in bladder cancer: the challenge of next generation sequencing in tissues and biofluids. Int J Cancer 138(10): 2334-2345.

Montironi R, Lopez-Beltran A (2005) The 2004 WHO classification of bladder tumors: a summary and commentary. Int J Surg Pathol 13(2): 143-153.

Nersesyan A, Kundi M, Fenech M, Bolognesi C, Misik M, Wultsch G, Hartmann M, Knasmueller S (2014) Micronucleus assay with urine derived cells (UDC): a review of its application in human studies investigating genotoxin exposure and bladder cancer risk. Mutat Res Rev Mutat Res 762: 37-51.

Peng Q, Mo C, Tang W, Chen Z, Li R, Zhai L, Yang S, Wu J, Sui J, Li S, Qin X (2014) DNA repair gene XRCC3 polymorphisms and bladder cancer risk: a meta-analysis. Tumour Biol 35(3): 1933-1944.

Russo A, Modica F, Guarrera S, Fiorito G, Pardini B, Viberti C, Allione A, Critelli R, Bosio A, Casetta G, Cucchiarale G, Destefanis P, Gontero P, Rolle L, Zitella A, Fontana D, Frea B, Vineis P, Sacerdote C, Matullo G (2014) Shorter leukocyte telomere length is independently associated with poor survival in patients with bladder cancer. Cancer Epidemiol Biomarkers Prev 23(11): 2439-2446.

Sacerdote C, Guarrera S, Ricceri F, Pardini B, Polidoro S, Allione A, Critelli R, Russo A, Andrew AS, Ye Y, Wu X, Kiemeney LA, Bosio A, Casetta G, Cucchiarale G, Destefanis P, Gontero P, Rolle L, Zitella A, Fontana D, Vineis P, Matullo G (2013) Polymorphisms in the XRCC1 gene modify survival of bladder cancer patients treated with chemotherapy. Int $J$ Cancer 133(8): 2004-2009.

Serra H, Da Ines O, Degroote F, Gallego ME, White CI (2013) Roles of XRCC2, RAD51B and RAD51D in RAD51-independent SSA recombination. PLoS Genet 9(11): e1003971.

Sharma S, Dey P, Saikia UN, Nijhawan R (2012) Micronucleus scoring in urine cytology specimen by DNA-specific stain. Anal Quant Cytol Histol 34(1): 56-60.

Slyskova J, Korenkova V, Collins AR, Prochazka P, Vodickova L, Svec J, Lipska L, Levy M, Schneiderova M, Liska V, Holubec L, Kumar R, Soucek P, Naccarati A, Vodicka P (2012a) Functional, genetic, and epigenetic aspects of base and nucleotide excision repair in colorectal carcinomas. Clin Cancer Res 18(21): 5878-5887.

Slyskova J, Naccarati A, Pardini B, Polakova V, Vodickova L, Smerhovsky Z, Levy M, Lipska L, Liska V, Vodicka P (2012b) Differences in nucleotide excision repair capacity between newly diagnosed colorectal cancer patients and healthy controls. Mutagenesis 27(4): 519-522.

Soloway MS (2013) Bladder cancer: lack of progress in bladder cancer-what are the obstacles? Nat Rev Urol 10(1): 5-6.
Sylvester RJ, van der Meijden AP, Oosterlinck W, Witjes JA, Bouffioux C, Denis L, Newling DW, Kurth K (2006) Predicting recurrence and progression in individual patients with stage Ta $\mathrm{T} 1$ bladder cancer using EORTC risk tables: a combined analysis of 2596 patients from seven EORTC trials. Eur Urol 49(3): 466-475.

Turinetto V, Pardini B, Allione A, Fiorito G, Viberti C, Guarrera S, Russo A, Anglesio S, Ruo Redda MG, Casetta G, Cucchiarale G, Destefanis P, Oderda M, Gontero P, Rolle L, Frea B, Vineis P, Sacerdote C, Giachino C, Matullo G (2016) H2AX phosphorylation level in peripheral blood mononuclear cells as an event-free survival predictor for bladder cancer. Mol Carcinog 55(11): 1833-1842.

Vafa O, Wade M, Kern S, Beeche M, Pandita TK, Hampton GM, Wahl GM (2002) c-Myc can induce DNA damage, increase reactive oxygen species, and mitigate p53 function: a mechanism for oncogene-induced genetic instability. Mol Cell 9(5): 1031-1044.

Wang M, Yuan L, Wu D, Zhang Z, Yin C, Fu G, Wei Q (2010) A novel $\mathrm{XPF}-357 \mathrm{~A}>\mathrm{C}$ polymorphism predicts risk and recurrence of bladder cancer. Oncogene 29(13): 1920-1928.

Wang Y, Li Z, Liu N, Zhang G (2014) Association between CCND1 and XPC polymorphisms and bladder cancer risk: a meta-analysis based on 15 casecontrol studies. Tumour Boil 35(4): 3155-3165.

Wei H, Kamat A, Chen M, Ke HL, Chang DW, Yin J, Grossman HB, Dinney CP, Wu X (2012) Association of polymorphisms in oxidative stress genes with clinical outcomes for bladder cancer treated with Bacillus Calmette-Guerin. PLoS One 7(6): e38533.

Witjes JA, Comperat E, Cowan NC, De Santis M, Gakis G, Lebret T, Ribal MJ, Van der Heijden AG, Sherif A (2014) EAU guidelines on muscle-invasive and metastatic bladder cancer: summary of the 2013 guidelines. Eur Urol 65(4): 778-792.

Zhu G, Su H, Lu L, Guo H, Chen Z, Sun Z, Song R, Wang X, Li H, Wang Z (2016) Association of nineteen polymorphisms from seven DNA repair genes and the risk for bladder cancer in gansu province of China. Oncotarget 7(21): 31372-31383.

Zijno A, Saini F, Crebelli R (2007) Suitability of cryopreserved isolated lymphocytes for the analysis of micronuclei with the cytokinesis-block method. Mutagenesis 22(5): 311-315.

This work is published under the standard license to publish agreement. After 12 months the work will become freely available and the license terms will switch to a Creative Commons AttributionNonCommercial-Share Alike 4.0 Unported License.

Supplementary Information accompanies this paper on British Journal of Cancer website (http://www.nature.com/bjc) 